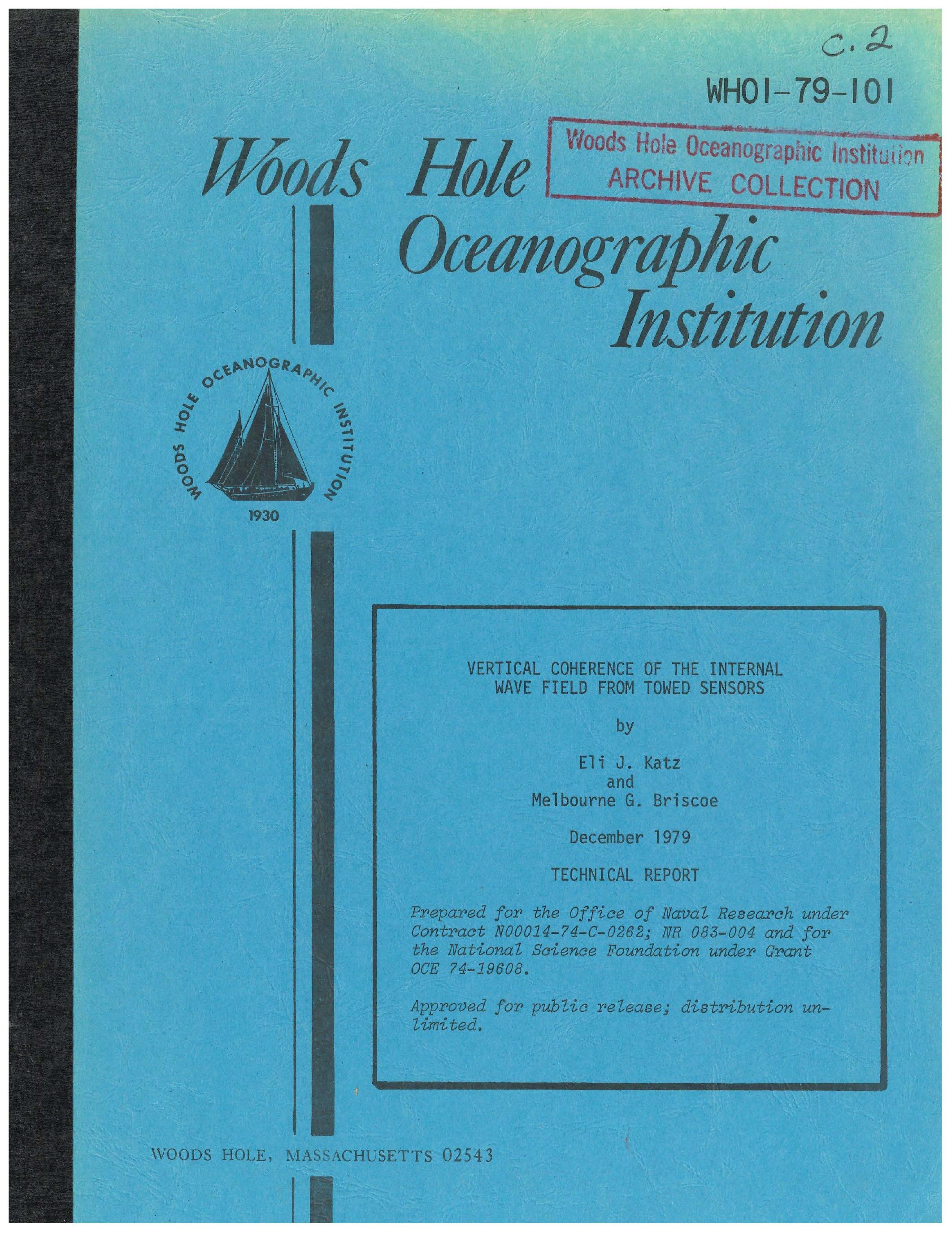


WHOI-79- 101

\title{
VERTICAL COHERENCE OF THE INTERNAL \\ WAVE FIELD FROM TOWED SENSORS
}

\author{
by \\ Eli J. Katz \\ and \\ Me]bourne G. Briscoe \\ WOODS HOLE OCEANOGRAPHIC INSTITUTION \\ Woods Hole, Massachusetts 02543
}

December 1979

TECHNICAL REPORT

Prepared for the Office of Naval Research under Contract N00014-74-C-0262; NR 083-004 and for the National Science Foundation under Grant OCE 74-19608.

Reproduction in whole or in part is permitted for any purpose of the United States Goverment. In citing this report in a bibliography, the reference given should be to "Journal of Physical Oceanography, Vol. 9, No. 3, May 1979, pp. 518-530". Approved for public release; distribution unlimited. Approved for Distribution: Valentine Worthington, Chairman Department of Physical Oceanography 
Reprinted from Journal of Physical Oceanography, Vol. 9, No. 3, May 1979

American Meteorological Society

Printed in U. S. A.

Vertical Coherence of the Internal Wave Field from Towed Sensors

Eli J. Katz and Melbourne G. Briscoe 


\title{
Vertical Coherence of the Internal Wave Field from Towed Sensors ${ }^{1}$
}

\author{
Eli J. Katz ${ }^{2}$ and Melbourne G. Briscoe \\ Woods Hole Oceanographic Institution, Woods Hole, MA 02543
}

(Manuscript received 15 August 1978, in final form 20 November 1978)

\begin{abstract}
Constant depth and isopycnal-following tows are used to estimate the towed vertical coherence of the internal wave field, at vertical separations of $8.5,18,28$ and $70 \mathrm{~m}$. The depths of the tows are $\sim 750 \mathrm{~m}$ at the maximum of the buoyancy frequency in the main thermocline of the Sargasso Sea, and near $350 \mathrm{~m}$ in the buoyancy frequency minimum between the main and seasonal thermoclines.

The towed spectra and towed vertical coherence are compared with three model spectra (GM75, GM76 and IWEX): at $750 \mathrm{~m}$ the agreement between data and models is very good, with IWEX being slightly better. At $350 \mathrm{~m}$ several of the measured towed vertical coherence spectra are more complex than the spectra from the deeper tows; there are anomalously high coherences in a band from 0.7 to 2 cycles per kilometer that are not predictable by the models. We suggest this coherence bump may be evidence of Eckart resonance, i.e., modes tunneling between the two thermoclines into the region of low buoyancy frequency.
\end{abstract}

\section{Background}

The present decade has witnessed an intense observational effort to describe the space-time energy density spectrum of internal waves; this kinematical description is needed for oceanographic studies of the energetics of the internal wave field and the role it plays in mixing the ocean, and for non-oceanographic studies (e.g., underwater acoustic propagation) that assume the internal wave field is a source of fluctuations that must be modeled statistically to be dealt with. Most investigations have utilized a single observational technique (Briscoe, 1975). The resulting continuous time or space series then gives a projection of the internal wave field along a single axis of wave vector-frequency space. If one can assume that some part of the internal wave field is statistically stationary and homogeneous within a wide geographic area most of the time, then these diverse individual observations of limited dimensional perspective can be combined to yield a useable description of the multidimensional spectrum.

With the latter in mind, and in the absence of a comprehensive dynamical model of internal waves, Garrett and Munk (1972) proposed a kinematical model (GM72). They succeeded in demonstrating that a single space-time energy spectrum could be synthesized which was compatible with most of the then-available projections of the energy spectrum.

\footnotetext{
${ }^{1}$ W.H.O.I. Contribution No. 4205.

${ }^{2}$ Present affiliation: Lamont-Doherty Geological Observatory of Columbia University, Palisades, NY 10964.
}

This was then modified in Garrett and Munk [1975 (GM75)] to be consistent with several new measurements, and various investigators have since proposed further modifications [Bell, 1976; Cairns and Williams, 1976; Desaubies, 1976 (the combination denoted by GM76); Müller et al., 1978 (IWEX)].

Data from tows have been used in the model building from the beginning. GM72 was fitted to two horizontal wavenumber displacement spectra (based on the vertical displacements of specified isotherms from towed thermistor chains (Charnock, 1965; Lafond and Lafond, 1971) in the wavenumber range of 0.1 to 10.0 cycles per kilometer $(\mathrm{cpkm})$. Both tows were in the shallow seasonal thermocline, but from different oceans. Data at higher wavenumbers, from isobaric tows at depths in and well below the Pacific main thermocline by Ewart, were initially rejected as resulting from oceanic finestructure. Katz (1973) introduced a new data set from the main thermocline of the southern Sargasso Sea which overlapped both the previous high and low wavenumber spectra. When combined with Katz (1975) and Zenk and Katz (1975) it describes a continuous displacement spectrum over the wavenumber band $10^{-2}$ to nearly $10^{3} \mathrm{c} \mathrm{km}^{-1}$. All the above spectra, including results by Bell (1976), are now well modeled by the recent internal wave models. In this intercomparison the energy density of the vertical displacement field is weighted by the local buoyancy frequency, which ranges from 0.5 to 6.0 cycles per hour ( $\mathrm{cph}$ ), a scaling on the basis of the WKB solution of the linear internal wave equation that was first tested by Fofonoff and Webster (1971). 
Despite the agreement between model and data, it is incorrect to conclude that the five-decade wavenumber band of energy density can be completely attributed to internal gravity waves. At the low wavenumber end, quasi-geostrophic displacements enter in (Wunsch, 1975) and, at high wavenumbers, sampling of finestructure yields an internal wavelike spectrum (e.g., Phillips, 1971). Other processes as well, for example blobs of water of a different temperature-salinity character, may show up as temperature fluctuations in the mid-range of wavenumbers; if these blobs have small vertical scales and large horizontal scales, then they can be misinterpreted in tow experiments as low-frequency internal wave fluctuations (cf. Bell, 1976). Unlike the frequency spectrum, which is band-limited by the inertial and buoyancy frequencies, the wavenumber band of internal waves is undelineated a priori. Observed displacement and coherence spectra have not yet identified the lower wavenumber limit of internal wave dominance. At high wavenumbers, McKean and Ewart (1974) have attempted to distinguish between internal waves and finestructure; suggesting a limit of about $20 \mathrm{cpkm}$.

The spectra of vertical density profiles complement the spectra of towed displacement spectra, and rapid vertical profiling together with towed arrays are partial attempts to obtain simultaneous information in both horizontal and vertical wavenumber space. For example, thermistor chains are capable of observing a swath in the horizontal and vertical wavenumber plane and Bell (1976) has presented some unique results for near-surface tows.

\section{Introduction}

The present paper describes the results of towing two instrumented fish at several fixed vertical separations between the seasonal and main thermocline (at a subsurface minimum in buoyancy frequency) and in the main thermocline (subsurface maximum) of the Sargasso Sea. By computing the coherence between the two temperature sensors one measures a weighted, integrated effect of vertical wavenumbers as a function of horizontal wavenumber.

The vertical coherence between two towed sensors provides a projection of the wavenumberfrequency spectrum that is imperfect in Fourier space (we would prefer some frequency information on the field) but is convenient in physical space (observations are possible at a range of depths, and in different spatial locations).

Analytically, Garrett and Munk (1972) defined a towed ventical coherence as the coherence between measurements of vertical displacement by two towed instruments vertically separated. It has not been measured directly. Instead, it is assumed here and usually elsewhere that the coherence between temperature signals at two constant depths adequately describes the vertical displacement of two isopycnal surfaces having that same vertical separation in the absence of any perturbations. The adequacy of the description depends on the correctness of the following assumptions: in the range of values observed during a particular tow, the temperaturesalinity correlation is one-to-one and linear, and the undisturbed vertical temperature gradient is linear and constant. The first condition is generally satisfied at the depths (best at our deepest depths; worst at our shallowest) and in the areas to be discussed, though the occasional presence of Gulf Stream rings could upset some shallow tows. A measure of how well the second condition is satisfied can be seen by comparing the measured temperature gradients presented below. We principally justify these assumptions by showing general agreement between data and model.

\section{Experimental design and data analysis}

The two instrumented fish have been described by Hess and Nowak (1974) and Katz and Witzell, Jr. (1979). The upper fish (Fig. 1) is depth-controlled by electrical command from the ship. The lower fish is weighted by a $150 \mathrm{~kg}$ lead centerboard. The general procedure was to tow the fish at constant depth, though several isotherm (isopycnal) following tows were also included. The ability to maintain a constant depth is important to the results, because the tow depth variations tend to increase coherence between the recorded signals (at the wavenumber of the depth variations) and thereby bias the results. The root-mean-square (rms) variation of vertical displacement of an isopycnal surface in the main thermocline of the Sargasso Sea (Katz, 1975) is less than $10 \mathrm{~m}$ for all wavenumbers $>10^{-2} \mathrm{cpkm}$ (with the linear trend excluded) and, at wavenumbers $>1$ $\mathrm{cpkm}$, it is of order $1 \mathrm{~m}$. For the coherence spectrum not to be contaminated, the variance of the tow depth fluctuation should be smaller than that of the displacement spectrum in all wavebands.

In the present work, the separation between the two fish varied no more than $1 \%$, but the depth of the pair of fish had a typical rms variation of about $1 \mathrm{~m}$. This can be partially compensated for by correcting the time (i.e., space) series of temperature at each fish by the depth variation multiplied by the temperature gradient, but this is only an approximate procedure. It is not even obvious whether the best results would be obtained by using the instantaneous local vertical gradient sensed by the two fish, or by the mean gradient observed between them, since neither is exactly correct. In practice both methods of correction reduced the coherence at wavenumbers $>1 \mathrm{cpkm}$ relatively the same amount, and left the coherence at smaller wavenum- 


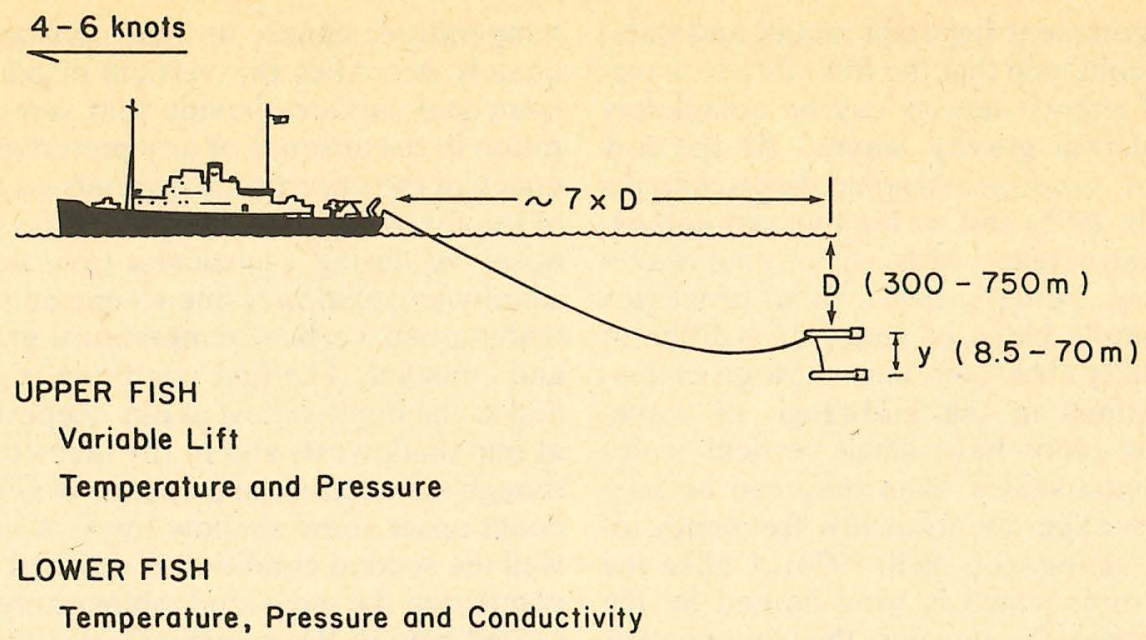

FIG. 1. Deployment of towed sensors.

bers unchanged. All coherences to be discussed are from these corrected time series. Typical spectra of the depth fluctuations of the tow (plotted on a variance preserving scale) are shown in Fig. 2 with the area for a $1 \mathrm{~m}$ rms displacement indicated.

The tows were made at speeds between 4-6 kt over ground and data were sampled every second so that the average spatial sample rate was $2.5 \mathrm{~m}$. All data were averaged into $100 \mathrm{~m}$ (or longer) lengths to reduce both the noise ${ }^{3}$ and the data quantity to be handled.

Two areas, both over deep ocean, were towed

${ }^{3}$ Depth sensitivity was $0.1 \mathrm{db}$; temperature sensitivity about $1 \times 10^{-3}{ }^{\circ} \mathrm{C}$ which is equivalent to the depth sensitivity in the smallest gradients encountered $\left(8 \times 10^{-3}{ }^{\circ} \mathrm{C} \mathrm{db} \mathrm{db}^{-1}\right)$. The sensors are from the Plessey 9007 model series. The relatively slow response of the temperature sensor $(0.5 \mathrm{~s})$ and the absolute calibration of the sensors are not of prime concern. in $-300 \mathrm{n}$ mi east of Bermuda and 30 to $120 \mathrm{n} \mathrm{mi}$ north of Bermuda. The temperature and buoyancy frequency profiles (Fig. 3) indicate that the water columns were similar to the east and immediately north of Bermuda (STD nos. 1 and 4), but varied further north (STD no. 5). In the latter, the seasonal and main pycnocline are displaced $150 \mathrm{~m}$ downward suggesting the presence of an anticyclonic eddy. As a consequence, the plan to locate tows in the local minimum and maximum of buoyancy frequency is not clearly accomplished in the most northern tows.

An annotated list of depth controlled tows is given in Table 1. Each of these proved long enough to measure at least 0.7 squared-coherence in the smallest wavenumber bands. The larger the separation (and presumably the higher the buoyancy frequency) the more track length required. Since it is the intention to combine all these data into a single

TABLE 1. Annotated list of constant depth tows and STD stations.

\begin{tabular}{|c|c|c|c|c|c|c|c|c|c|}
\hline \multirow[b]{2}{*}{$\begin{array}{l}\text { Tow } \\
\text { no. }\end{array}$} & \multirow[b]{2}{*}{$\begin{array}{c}\text { Date } \\
(1975)\end{array}$} & \multirow[b]{2}{*}{$\begin{array}{c}\text { Start } \\
\text { location }\end{array}$} & \multirow[b]{2}{*}{$\begin{array}{l}\text { Head- } \\
\text { ing }\end{array}$} & \multirow{2}{*}{$\begin{array}{c}\text { Track } \\
\text { length } \\
(\mathrm{km})\end{array}$} & \multirow{2}{*}{$\begin{array}{l}\text { Vertical } \\
\text { separation } \\
\text { (m) }\end{array}$} & \multicolumn{2}{|c|}{$\begin{array}{l}\text { Bottom } \\
\text { sensor }\end{array}$} & \multirow{2}{*}{$\begin{array}{l}\text { Buoyancy } \\
\text { frequency } \\
\text { (cph) }\end{array}$} & \multirow{2}{*}{$\begin{array}{c}\text { Measured } \\
d T / d z \\
\left({ }^{\circ} \mathrm{C} \mathrm{m}^{-1}\right)\end{array}$} \\
\hline & & & & & & $\begin{array}{c}\bar{p} \\
(\mathrm{~m})\end{array}$ & $\begin{array}{c}\bar{T} \\
\left({ }^{\circ} \mathrm{C}\right)\end{array}$ & & \\
\hline 902 & 6 Oct & $60^{\circ} \mathrm{W} 31^{\circ} \mathrm{N}$ & East & 40 & 28 & 330 & 17.7 & 1.9 & $7.6 \times 10^{-3}$ \\
\hline 913 & 10 Oct & $60^{\circ} \mathrm{W} 30^{\circ} \mathrm{N}$ & West & 31 & 8.5 & 305 & 17.7 & 1.9 & $8.1 \times 10^{-3}$ \\
\hline 914 & $10 \mathrm{Oct}$ & $61^{\circ} \mathrm{W} 30^{\circ} 30^{\prime} \mathrm{N}$ & East & 23 & 8.5 & 770 & 10.8 & 2.6 & $2.5 \times 10^{-2}$ \\
\hline 931 & $14 \mathrm{Oct}$ & $59^{\circ} 30^{\prime} \mathrm{W} 30^{\circ} \mathrm{N}$ & West & 208 & 70 & 770 & 11.0 & 2.6 & $2.4 \times 10^{-2}$ \\
\hline 932 & 15 Oct & $63^{\circ} 30^{\prime} \mathrm{W} 30^{\circ} \mathrm{N}$ & East & 74 & 70 & 330 & 18.0 & 1.9 & $7.1 \times 10^{-3}$ \\
\hline 942 & 17 Oct & $64^{\circ} 30^{\prime} \mathrm{W} 33^{\circ} \mathrm{N}$ & West & 27 & 28 & 755 & 11.8 & 2.5 & $1.8 \times 10^{-2}$ \\
\hline 962 & 22 Oct & $64^{\circ} \mathrm{W} 34^{\circ} 30^{\prime} \mathrm{N}$ & South & 34 & 18 & 655 & 15.6 & 2.3 & $1.6 \times 10^{-2}$ \\
\hline 964 & 23 Oct & $67^{\circ} \mathrm{W} 34^{\circ} \mathrm{N}$ & North & 75 & 18 & 350 & 18.5 & 2.0 & $6.6 \times 10^{-3}$ \\
\hline $\begin{array}{l}\text { STD } \\
\text { no. }\end{array}$ & Date & Location & & & & & & & \\
\hline 1 & 8 Oct & $61^{\circ} \mathrm{W} 31^{\circ} 30^{\prime} \mathrm{N}$ & & & & & & & \\
\hline 4 & 19 Oct & $64^{\circ} \mathrm{W} 33^{\circ} \mathrm{N}$ & & & & & & & \\
\hline 5 & 24 Oct & $67^{\circ} \mathrm{W} 35^{\circ} \mathrm{N}$ & & & & & & & \\
\hline
\end{tabular}




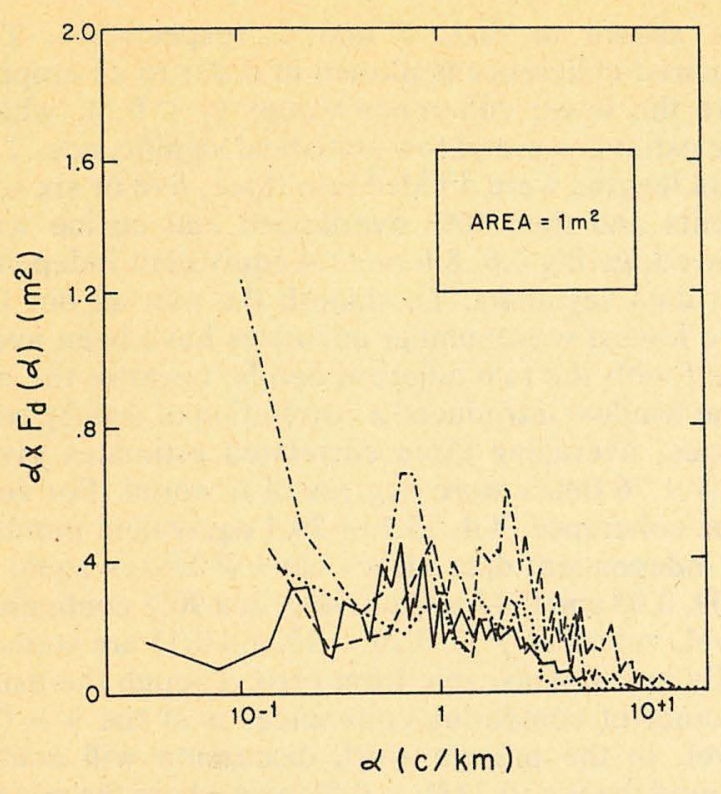

FIG. 2. Variance-preserving plot of the autospectrum of the tow depth from four representative tows.

representation of the dependence of vertical coherence on horizontal wavenumber, it will have to be postulated that each tow was in a statistically similar internal wave field. This can be thought of as a working hypothesis which will be partially verified by the consistency of the final result.

A less sensitive test can be applied first, though: are all the vertical displacement spectra statistically similar? Fig. 4 is a plot of seven displacement spectra, obtained from the temperature spectra during each tow divided by the square of the mean temperature gradient observed during that tow, and weighted by the local buoyancy frequency. The last two factors are given in Table 1 . The figure indicates that the spectra do indeed closely approximate one another. Tow no. 964 (unplotted) indicated a halfdecade higher energy at low wavenumbers but it is probably a spurious result which could easily result from applying an inappropriate scaling factor when sampling in the eddy.

Also shown in Fig. 4, for comparison, is the model spectrum of IWEX (see Appendix). The IWEX model spectrum is derived from a smoothing of the results presented by Müller et al. (1978), and in principle should be the best description of the internal wave field for our experiments because it is more detailed than GM75 or GM76 and was derived solely from Sargasso Sea data. The displacement spectra of Fig. 4 are very similar to those computed from data $300 \mathrm{n}$ mi west of Bermuda earlier (the MODE spectra, Fig. 2, Katz, 1975), which was obtained by tracking a specific isotherm. The latter, in turn, was shown to agree with the results of other investigators cited earlier. Therefore, at this level of analysis, the present data sets do not appear to be either different from one another, or unusual with respect to other observations.

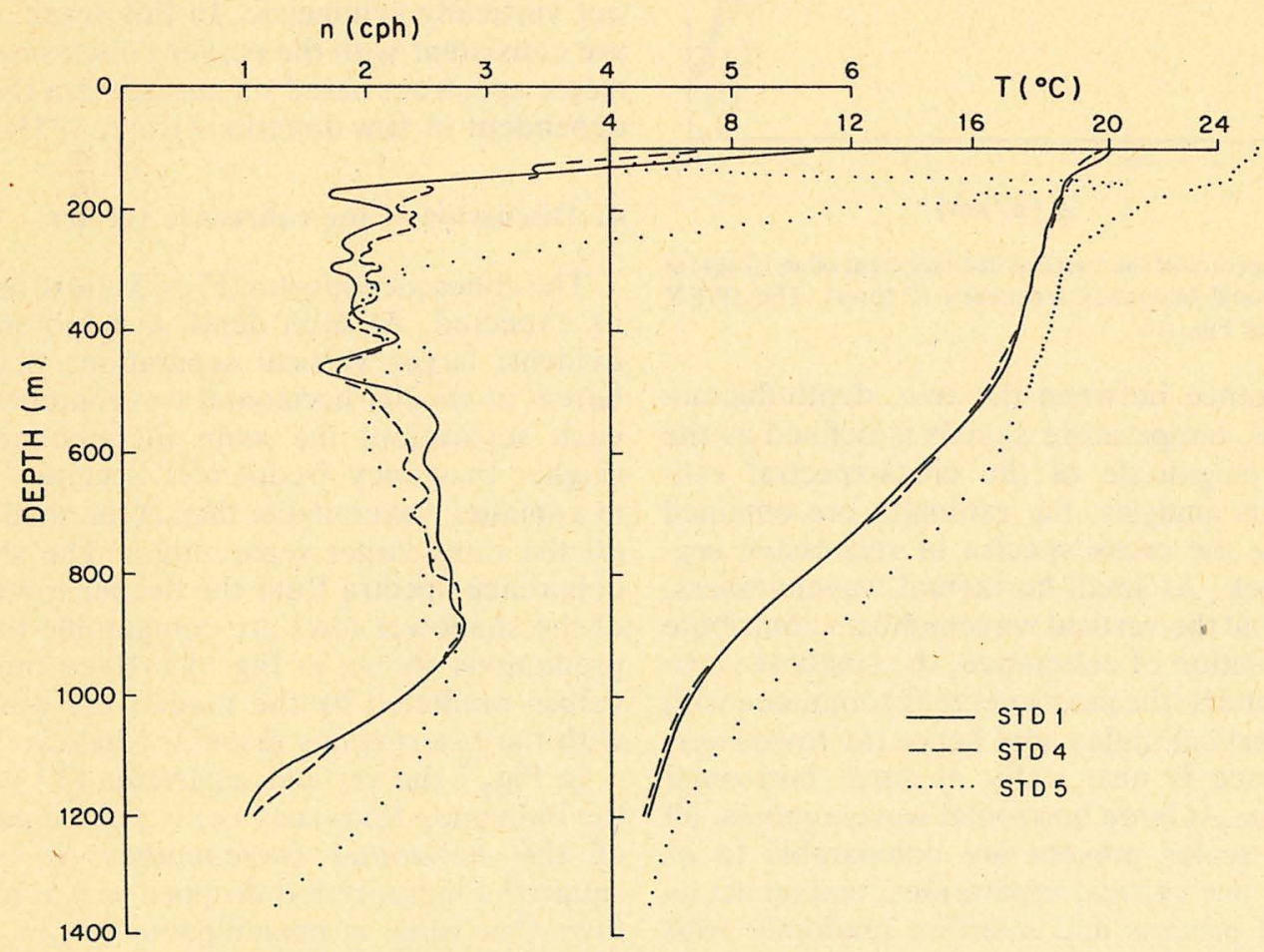

FIG. 3. Buoyancy frequency and temperature profiles from the tow areas. Time and locations are given in Table 1. 


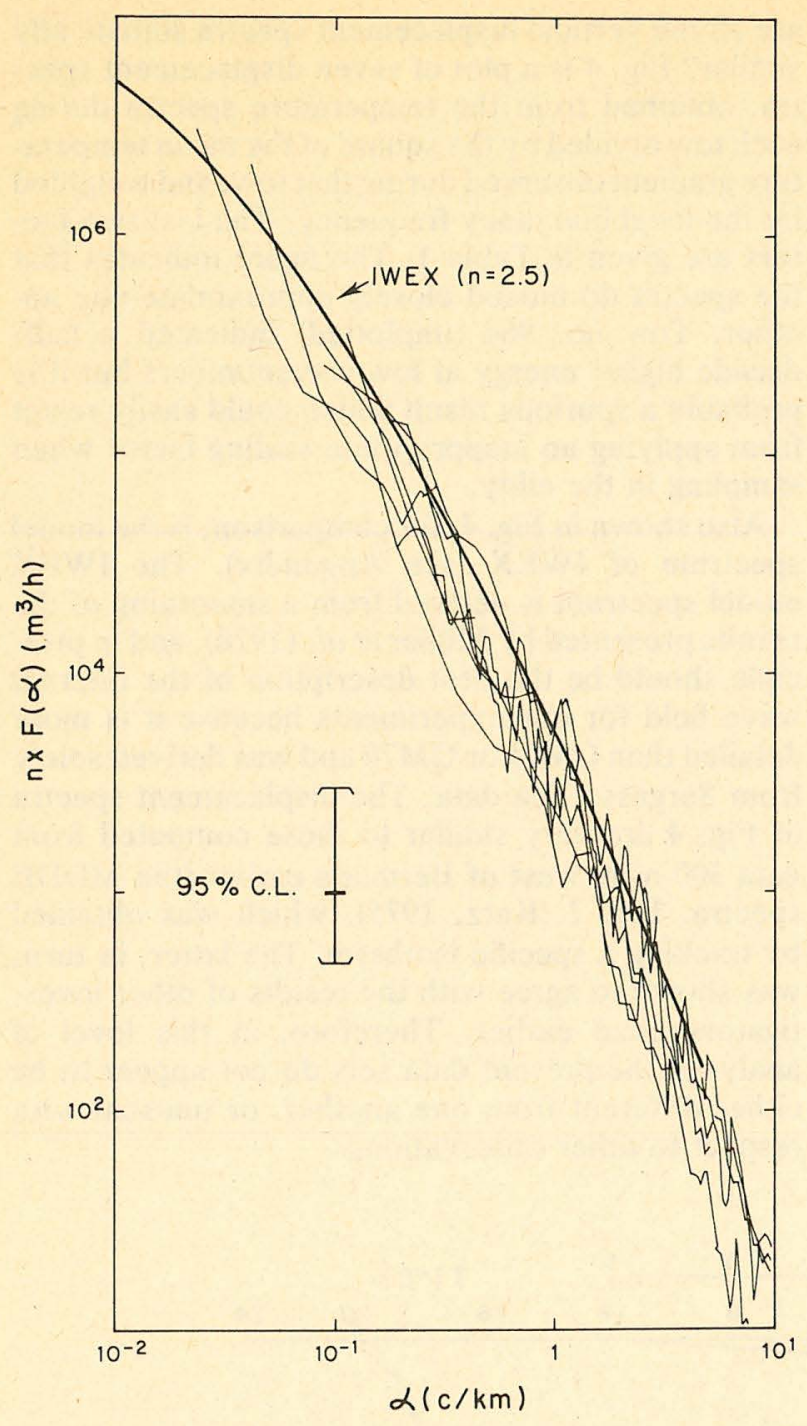

FIG. 4. Autospectra of the vertical displacement of an isotherm scaled by the local buoyancy frequency ( 7 tows). The IWEX spectrum is from Fig. A1.

The coherence between the two, depth-fluctuation adjusted, temperature signals is defined as the normalized magnitude of the cross-spectral estimates. In this analysis, the estimates are obtained by averaging the cross spectra of successive segments of track. At small horizontal wavenumbers, even though all the vertical wavenumbers contribute to the degradation of coherence, the smallest vertical wavenumbers (the most energetic) dominate with their large vertical scales, and hence the towed vertical coherence is near unity at small horizontal wavenumbers. At large horizontal wavenumbers, all the vertical scales present are comparable to or smaller than our vertical separations, and so act as a broadband process and interfere randomly with each other to cause low coherence.

The vertical coherences for the eight selected tows are shown in Figs. 5 and 6, respectively. The squared-coherence is plotted in order to de-emphasize the lower coherence values $(\hat{\gamma}<0.5)$, where the estimates are of low statistical significance. The data lengths were divided into three, five or six segments and then $50 \%$ overlapped and cosine windowed, giving $4.8,8.6$ or 11.4 equivalent independent data segments. To smooth the plot all but the two lowest wavenumber estimates have been averaged with the two adjacent bands; because the cosine window introduced a correlation of nearby estimates, averaging three correlated estimates gives only 1.76 times more degrees of freedom. For zero true coherence, $8.4,15.1$ or 20.1 equivalent number of independent data pieces have $\hat{\gamma}^{2}$ biases equal to $0.09,0.05$ and 0.04 respectively; at a $90 \%$ confidence level, values of $\hat{\gamma}^{2}<0.26,0.15$ and 0.11 are statistically indistinguishable from zero. Though the usual manner of comparing coherences is at the $\hat{\gamma}=0.5$ level, in the present work discussion will center around the $\hat{\gamma}=0.7\left(\hat{\gamma}^{2}=0.5\right)$ level where the results are statistically reliable at the $90 \%$ confidence level.

The phase angle between the two signals tends to be zero at the smallest wavenumbers and then becomes random as the estimated coherence falls below the significance level. There are apparent exceptions to this in the data at small wavenumbers, but none that are statistically significant. Phase spectra are therefore not discussed. In any case, for an isotropic internal wave spectrum the phase of the towed vertical coherence is zero even if the field is not vertically symmetric. In this sense, the results are consistent with the earlier conclusion of an isotropic spectrum based on autospectra that were independent of tow direction (Katz, 1973).

\section{Discussion of the coherence spectra}

The coherence spectra (Figs. 5 and 6) are generally as expected. At each depth a monotonic trend is evident: larger vertical separations become incoherent at smaller horizontal wavenumbers while, at each separation, the main thermocline spectrum (higher buoyancy frequency) becomes incoherent at a smaller wavenumber than at the shallower depth (at the three larger separations). The shape of the coherence spectra from the deeper tows and some of the shallower tows are comparable to the model predictions shown in Fig. A2. Even the numerical values predicted by the models are observed, but with the reservations discussed below.

In Fig. 7 the vertical separation $(Y)$ weighted by the buoyancy frequency $(n)$ is plotted as a function of the horizontal wavenumber $(\alpha)$ where the squared-coherence has dropped to 0.5 . In the $750 \mathrm{~m}$ tows this value is unambiguous but at $350 \mathrm{~m}$, the 8.5 and $28 \mathrm{~m}$ spectra regain coherence after dropping below $\hat{\gamma}^{2}=0.5$ and both values are plotted. Also 


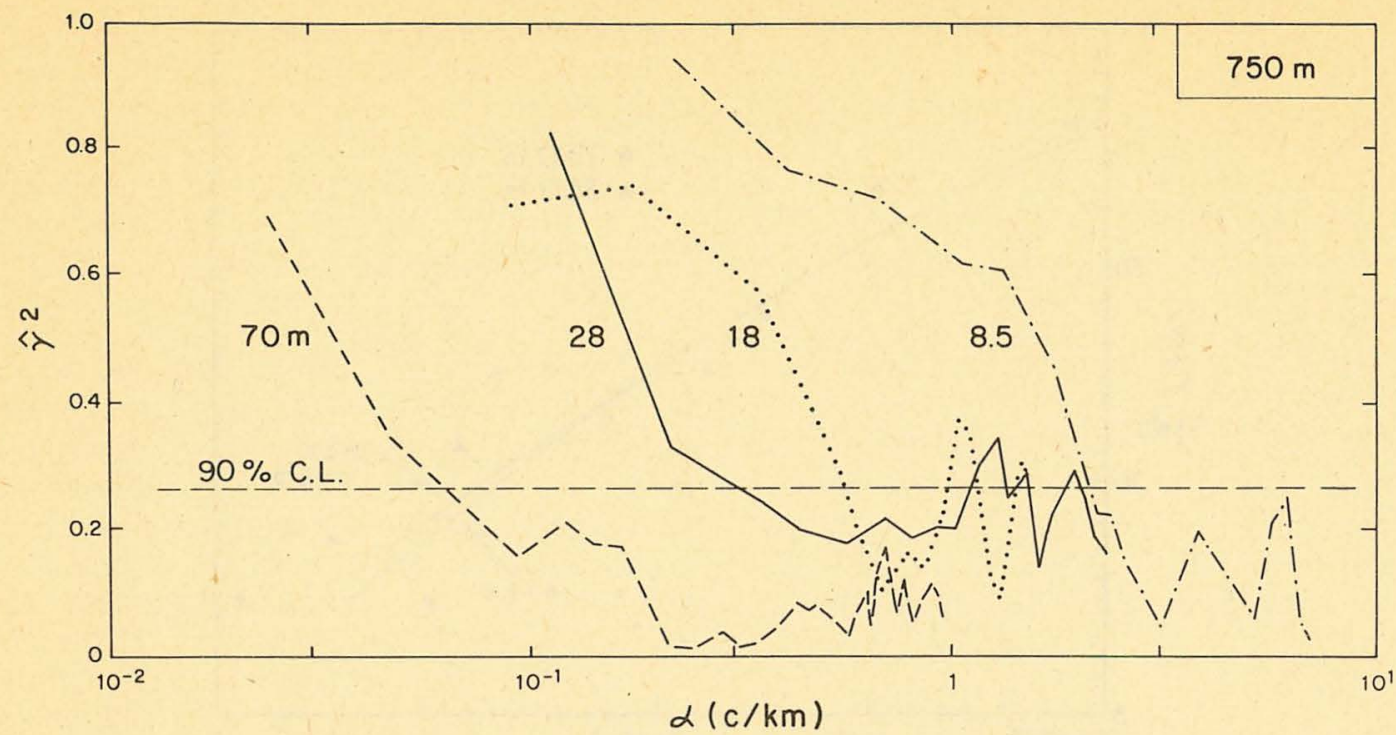

FIG. 5. The vertical squared-coherence spectra of four tows in the main thermocline (depths about $750 \mathrm{~m}$ ). Vertical separation (m)
Tow number
Equivalent independent data
segments

$\begin{array}{cccc}8.5 & 18 & 28 & 70 \\ 914 & 962 & 942 & 931 \\ 8.6 & 4.8 & 4.8 & 8.6\end{array}$

is the dominant scaling in the wavenumber-buoyancy range of the observations. The same is true of the other models, explaining the use of this scaling by Garrett and Munk (1975, Fig. 4) which generally predicts somewhat smaller values of $\alpha$ for which $\hat{\gamma}^{2}=0.5$ (Fig. A2).

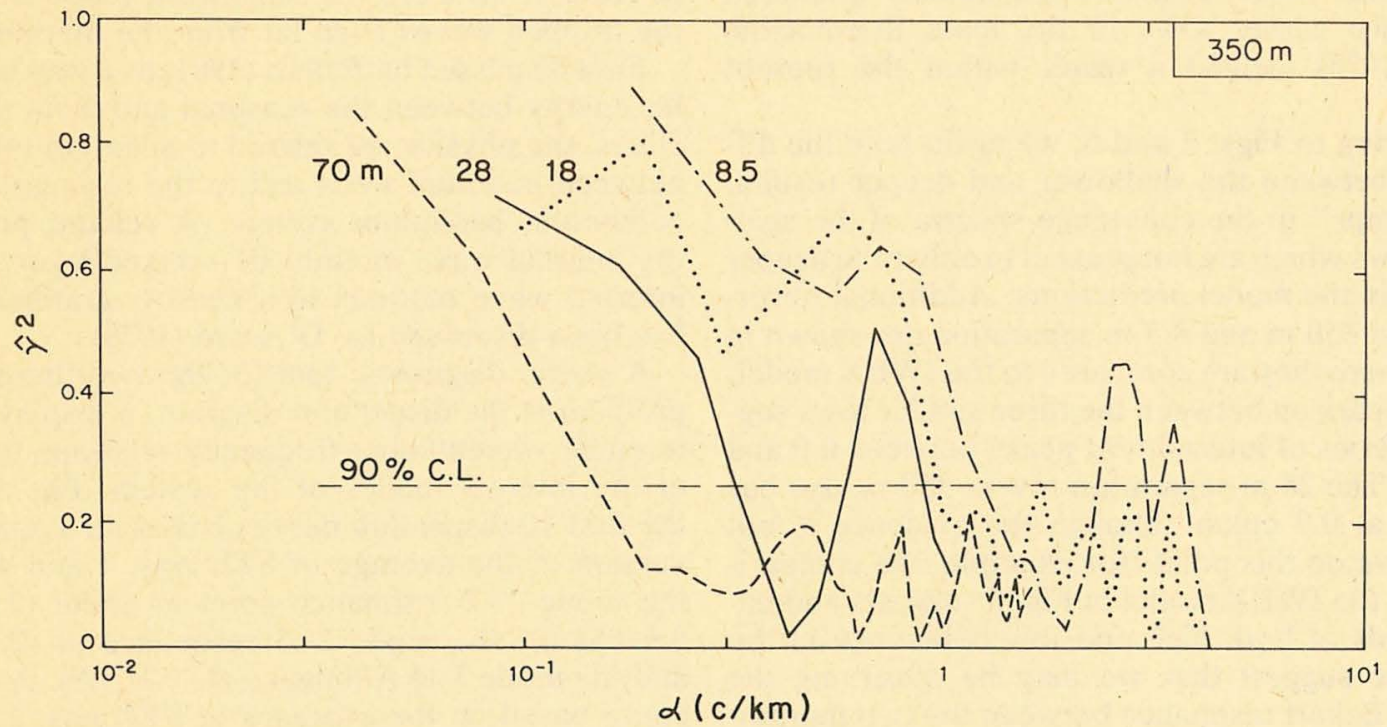

FIG. 6. The vertical squared-coherence spectra of four tows between the summer and main thermocline (depths about $350 \mathrm{~m}$ ).

$$
\begin{aligned}
& \text { Vertical separation }(\mathrm{m}) \\
& \text { Tow number } \\
& \text { Equivalent independent data } \\
& \text { segments }
\end{aligned}
$$

$\begin{array}{crrr}8.5 & 18 & 28 & 70 \\ 913 & 964 & 902 & 932 \\ 4.8 & 11.4 & 4.8 & 4.8\end{array}$




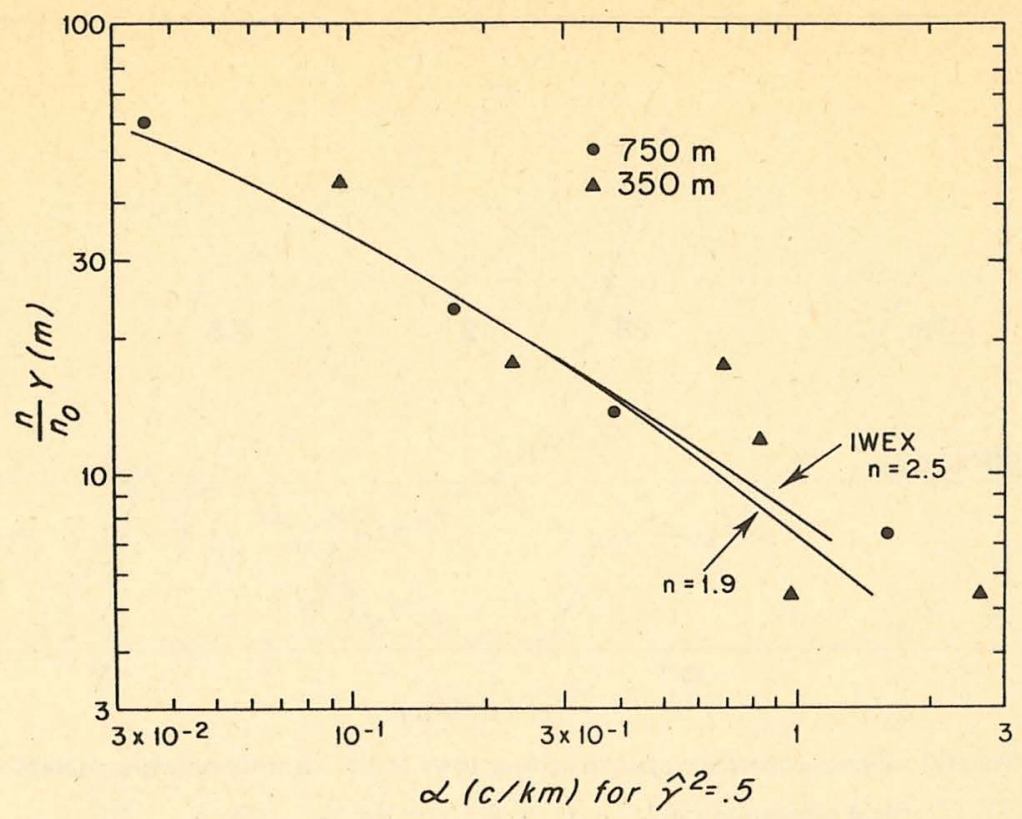

FIG. 7. Comparison of observed and IWEX-predicted horizontal wavenumber for 0.5 squared-coherence. Vertical separation is weighted by the buoyancy frequency ratio $n / n_{0}$, when $n_{0}=3 \mathrm{cph}$. The observed values are read off Figs. 5 and 6 . Solid lines are the IWEX model read off Fig. A2.

Previous investigators, namely LaFond and Charnock (quoted in Garrett and Munk, 1972) and Bell (1976), all found more coherent results than shown in Fig. 7. However, their observations were from tows within $120 \mathrm{~m}$ of the surface and it is not expected that there should be agreement with either the present observations or the models discussed here. Two earlier tows in the main thermocline (Katz, 1975) yielded a result within the present scatter.

Referring to Figs. 5 and 6 , we again note the difference between the shallower and deeper results: the "bumps" in the coherence spectra of the shallower tows which are not present in either the deeper tows or in the model predictions. Additional observations at $350 \mathrm{~m}$ and $8.5 \mathrm{~m}$ separation are shown in Fig. 8 where they are compared to the IWEX model. The comparison between the three similar tows suggests a series of intermittent peaks between 0.9 and $2 \mathrm{cpkm}$. The $28 \mathrm{~m}$ separation tow at $350 \mathrm{~m}$ also has a bump at $0.7 \mathrm{cpkm}$. Though the evidence is not conclusive on this point (for example, the comparison with the IWEX model in Fig. 8 suggests anomalous bands of both high and low coherence in the data), we suggest that we may be observing the result of Eckart resonance between the two thermoclines.

\section{Eckart resonance}

One physical phenomenon at $350 \mathrm{~m}$ that is not present at $750 \mathrm{~m}$ is the possibility of leakage or tun- neling of low-mode energy into the buoyancy frequency minimum between the thermoclines above and below. The higher frequency waves trapped in the thermoclines have exponentially decaying motions away from the thermoclines, but the exponential scale may be measured in hundreds or thousands of meters, so there are significant motions due to the trapped waves even far from the thermocline.

First discussed by Eckart (1961) as a way to transfer energy between the seasonal and main thermoclines, the physics are related to quantum tunneling between potential wells and to the resonances in a compound pendulum system. A related problem, the internal wave motions in a mixed layer, due to internal wave motions in a nearby stratified fluid, has been discussed by D'A'saro (1978).

A useful diagnostic tool for the two-thermocline problem is the dispersion diagram, a display of the possible wavenumber-frequency relations for each of the internal modes of the system. Fig. 9 gives the first 10 dispersion curves based on a smoothed version of the average of STD nos. 1 and 4 . Note the mode 1-2 resonance point at about $(2.1 \mathrm{cph}$, $0.6 \mathrm{cpkm})$, the mode $2-3$ resonance at $(2.5,2.4)$ and the mode 3-4 resonance at $(2.1,1.9)$. A similar curve based on the averages of STD nos. 1, 4 and 5 shifts the three resonance points to $(2.1,0.5),(2.4$, $1.7)$ and $(2.5,3.5)$.

The mode 1-2 resonance should dominate any observations because the energy present in the two lowest modes dominates, according to the models. The dominance should show up as a slight modula- 


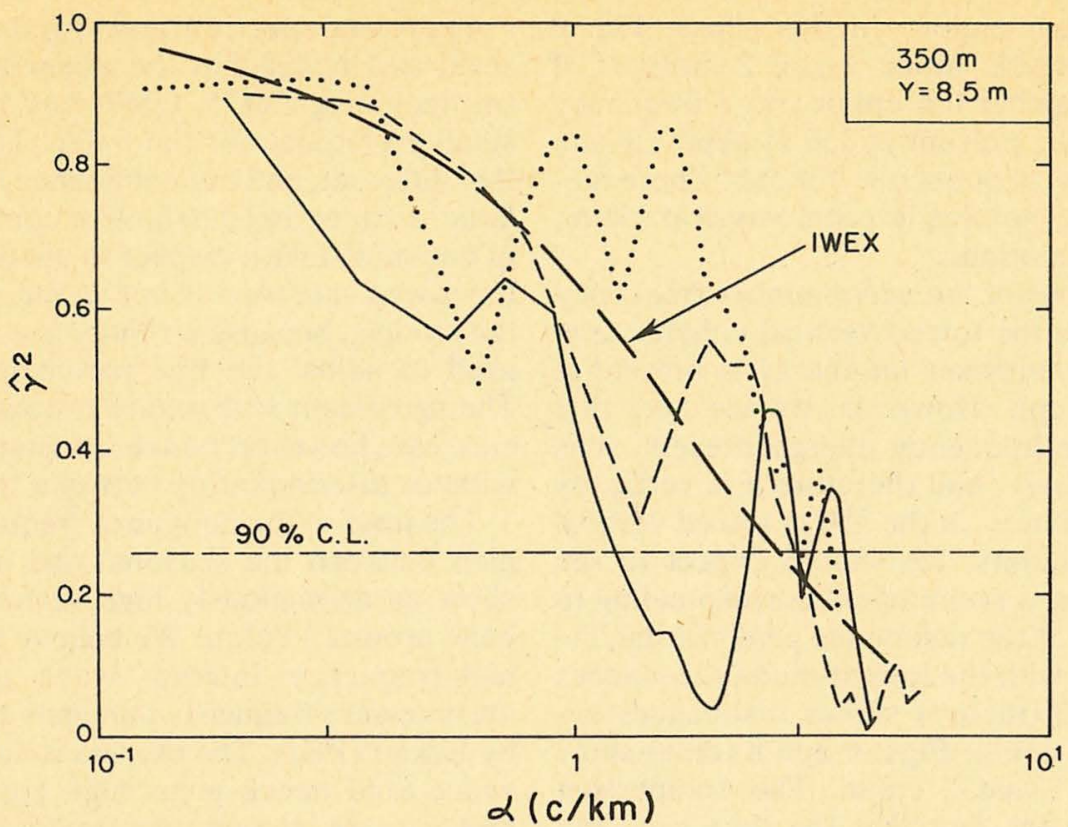

FIG. 8. The vertical squared-coherence spectra for three tows between the thermoclines at $8.5 \mathrm{~m}$ separation. Tow 913 is repeated from Fig. 6. The other two are two segments in the vicinity of a cold core ring encountered adjacent to Bermuda (Tow 951, described by Hogg et al., 1978). The solid line is the IWEX prediction from Fig. A2.

tion of the energy present in each of the two modes, with a modulation period proportional to the inverse of the frequency separation between the two modes at the resonance point. The wavelength of the modulation is similarly proportional to the inverse of the wavenumber separation at the resonance point.
From Fig. 9 this would give modulation characteristics for the mode $1-2$ resonance of some $4 \mathrm{~h}$ and $6 \mathrm{~km}$.

A different interpretation of the resonance points is that they indicate what wavenumbers and frequencies are best able to tunnel across the buoyancy

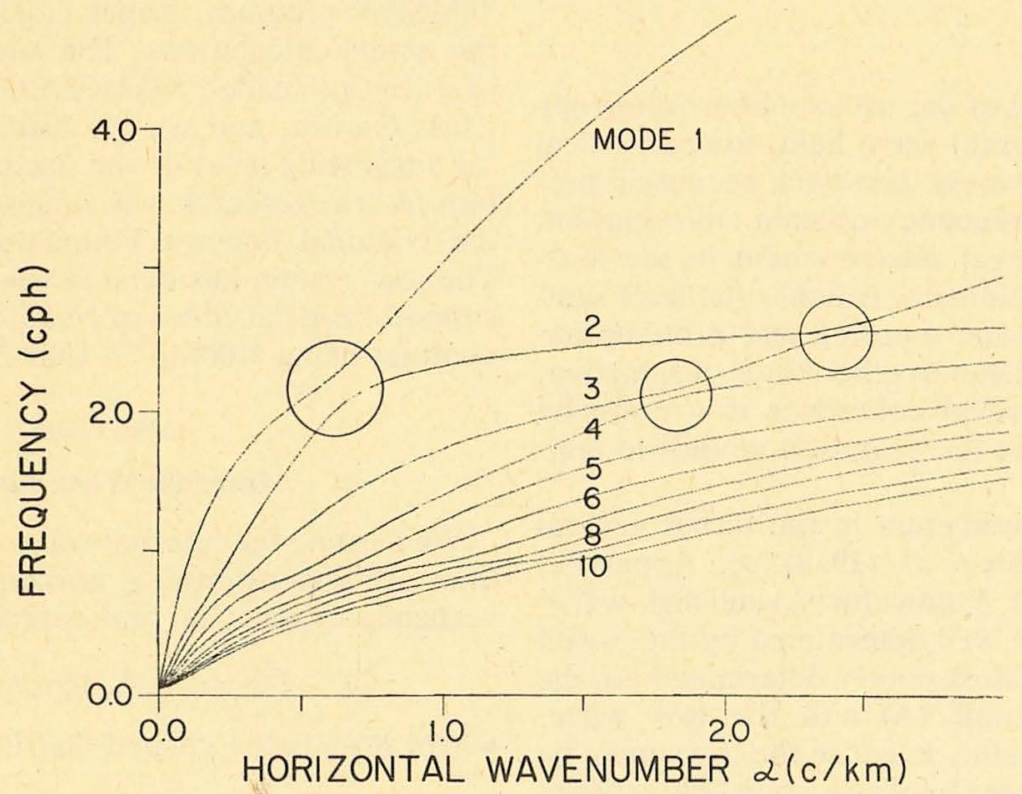

FIG. 9. Dispersion diagram for the first ten internal wave modes based on the smoothed and average buoyancy frequency profiles of STD Nos. 1 and 4 . Regions of resonance (i.e., tunneling) for the lower modes are circled. 
frequency minimum region. In this sense, Fig. 9 suggests that energetic mode 1 and 2 motions of horizontal wavenumber $0.6 \mathrm{cpkm}$ and a frequency of $2.1 \mathrm{cph}$ should be present at $350 \mathrm{~m}$ depth, where the local buoyancy frequency is $1.9 \mathrm{cph}$ ! These motions are, of course, not free internal waves at $350 \mathrm{~m}$, but rather forced motions.

In our integrations of the wavenumber-frequency spectrum to obtain the towed vertical coherence at $350 \mathrm{~m}$, the model supposes no energy is present at frequencies $>1.9 \mathrm{cph}$. However, we see here that not only is higher frequency energy present, it is low mode energy only, and therefore it is vertically highly coherent. Hence, in the $350 \mathrm{~m}$ towed vertical coherence observations, we should expect to see coherence peaks at wavenumbers corresponding to the wavenumbers of the resonance peaks in the dispersion diagrams, with the lowest-mode resonances dominating. Fig. 9 (theory) shows resonances between 0.6 and $2.4 \mathrm{cpkm}$; Figs. 6 and 8 (data) show peaks between 0.7 and $2 \mathrm{cpkm}$. The comparison is complicated by the fact that the data can only reflect the projection of the various wave modes in the plane of the tow.

Nonetheless, we hypothesize that the extra bumps in the $350 \mathrm{~m}$ coherences are evidence of internal waves tunneling between the seasonal and main thermoclines, i.e., Eckart resonances. Proof of the concept would require simultaneous frequency-domain observations (i.e., moored current meters; this is where our tows are deficient) and, preferably, direct observations of the modulation of the tunneling modes. These data are not available and we can go no further with the analysis.

\section{Conclusions}

For an assessment of the wavenumber-frequency character of the internal wave field, towed vertical coherence has an inherent drawback because it provides no direct frequency-domain information. However, it is a direct measurement in the horizontal wavenumber domain, which is the least sampled space in the usual mooring and profiling experiments. As an adjunct to other kinds of sampling, then, the towed vertical coherence is a powerful tool to help constrain the proposed models to realistic forms.

Of the various parameters in the rather general model given in Müller et al. (1978) [see Appendix] only total energy $\left(E_{0}\right)$, bandwidth $\left(j_{e}\right)$ and high-wavenumber slope $(t)$ are well determined by the towed vertical coherence. Most poorly determined are the low-wavenumber cutoff $(\Delta)$ and the low wavenumber slope $(s)$, mainly because the tows must be extremely long in order to obtain statistical reliability at such long scales, and because non-internal wave motions are particularly strong at those scales.
The towed spectrum and towed vertical coherence seem well modeled by the recent internal wave spectra, including GM75, GM76 and IWEX, with some small preference for the latter. The models are not that different, and our confidence in the data not that large, as to permit a definitive comment on the merit of one model with respect to another. Furthermore, the towed spectrum is not an independent check on the models, because a similar spectrum was initially used to adjust the free parameters of the model. The agreement with regard to towed vertical coherence can, however, be seen as supporting the models without discriminating between them.

The tows in the buoyancy frequency minimum region between the seasonal and main thermoclines show an anomalously high vertical coherence in a band around $1 \mathrm{cpkm}$. We believe this may be due to high-frequency internal wave tunneling through the buoyancy frequency minimum region, as proposed by Eckart (1961). The process is narrowband in mode space (and hence gives high coherences) because higher modes cannot tunnel sufficiently far (the solutions decay exponentially away from and between the two thermoclines).

Acknowledgments. The data were collected during cruise no. 127 of the R/V Chain, the next to the last cruise of a ship which served WHOI and the science of oceanography so admirably over many years. We wish to acknowledge Capt. Palmieri and his officers and crew for their assistance on this and many previous cruises. Warren E. Witzell, Jr., engineered the towing system. Maxine Jones programmed the data acquisition and processing. The spectral analysis was done with Mary Hunt's TIMSAN program. Roger Goldsmith programmed the model calculations. The integrations made use of a routine (called ROMBERG) supplied to us by Chris Garrett, and we are further indebted to him for suggesting most of the useful substitutions employed. The research was supported by a grant from the National Science Foundation (OCE74-19608). The tow system has been developed by continuous support from the Office of Naval Research, the latest contract being N00014-74-C0262; NR083-004.

\section{APPENDIX}

\section{Internal Wave Models}

We assume the internal wave spectrum (all quantities are dimensional) is horizontally isotropic and vertically symmetric, and describe it by

$$
E(\alpha, \omega)=E_{0} A(\alpha, \omega) B(\omega),
$$

where $B(\omega)$ is the cusped Garrett-Munk form

$$
B(\omega)=\frac{2}{\pi} \frac{\omega_{i}}{\omega}\left(\omega^{2}-\omega_{i}^{2}\right)^{-1 / 2}
$$


and the $A(\alpha, \omega)$ gives the wavenumber shape at each frequency. The Garrett-Munk spectra assume $A(\alpha, \omega)$ is self-similar, i.e.,

$$
A(\alpha, \omega)=\frac{A\left(\frac{\alpha}{\alpha_{*}}\right)}{\alpha_{*}},
$$

where $\alpha_{*}=\alpha_{*}(\omega)$ is a scale factor; this requires the $E(\alpha, \omega)$ wavenumber structure to have the same shape at each frequency, although the actual bandwidth might change.

The IWEX modeling (Müller et al., 1978, hereafter referred to as IWEX) used the same form as (A2), but allowed the parameters in the shape function to be frequency-dependent; this removes the similarity requirement introduced by Garrett and Munk. Some principal results from IWEX are included below.

The IWEX form for (A2) is

$A(\alpha, \omega)=\frac{A\left(\frac{\alpha}{\alpha_{*}}\right)}{\alpha_{*}}=\alpha_{*}{ }^{-1} \frac{I(t, s)}{\left[1+\left(\frac{\alpha-\Delta}{\alpha_{*}}\right)^{s}\right]^{t / s}}$,

where $I(t, s)$ is a normalization constant given by

$$
I(t, s)=\frac{s \Gamma\left(\frac{t}{s}\right)}{\Gamma\left(\frac{1}{s}\right) \Gamma\left(\frac{t-1}{s}\right)} .
$$

The parameter $\Delta$ describes a low-wavenumber cutoff at each frequency. Selected frequency-independent values of $t$ and $s$, for $\Delta=0$, produce GM72, GM75 and GM76 as special cases of (A4) (c.f. Table A1). The IWEX modeling yielded values for $\Delta, t$ and $s$ as functions of frequency; we will smooth the structure and use mostly constant values.
The scale wavenumber $\alpha_{*}$ is given by the simplified dispersion relation, i.e.,

$$
\alpha_{*}=\frac{j_{*}}{2 N b}\left(\omega^{2}-\omega_{i}^{2}\right)^{1 / 2},
$$

and is therefore related to the $j_{*}$ th mode. However, the appropriate scaling depends upon the choice of $t$ and $s$, which is inconvenient because we would prefer the parameters to be orthogonal, if possible. Defining an equivalent bandwidth,

$$
\alpha_{e}(\omega)=\frac{\left[\int_{0}^{\infty} A(\alpha, \omega) d \alpha\right]^{2}}{\int_{0}^{\infty}[A(\alpha, \omega)]^{2} d \alpha},
$$

analogous to the definition of a spectral bandwidth, yields

where

$$
\alpha_{e}=J(t, s) \alpha_{*},
$$

$$
J(t, s)=\frac{\left(\frac{2 t}{s}\right) \Gamma\left(\frac{1}{s}\right)}{s \Gamma\left(\frac{2 t-1}{s}\right)}\left(\frac{\Gamma\left(\frac{t-1}{s}\right)}{\Gamma\left(\frac{t}{s}\right)}\right)^{2} .
$$

IWEX shows that $j_{e}=J j_{*}$ is considerably better than $j_{*}$ for use as a bandwidth definition.

\section{Spectral Projections}

The towed spectrum is $\operatorname{TS}(\alpha)$, where

$$
T S=\frac{2}{\pi} \int_{\omega_{i}}^{n} \int_{\alpha}^{\infty}\left(\alpha_{1}{ }^{2}-\alpha^{2}\right)^{-1 / 2} E\left(\alpha_{1}, \omega\right) \overline{Z^{2}} d \alpha_{1} d \omega
$$

and $\overline{Z^{2}}$ is the wave function for a vertical displacement field, i.e.,

$$
\overline{Z^{2}}=\frac{b^{2} N}{n} \frac{\left(\omega^{2}-\omega_{i}{ }^{2}\right)}{\omega^{2}} .
$$

Using the substitutions

$$
\left.\begin{array}{rlrl}
\sec \phi & =\omega / \omega_{i}, & \mu & =2 J N b / j_{e} n \\
\left(z^{2}+1\right)^{1 / 2} & =\alpha_{1} / \alpha, & \nu & =n \alpha / \omega_{i} \\
\Delta & =j_{p} 2 N b\left(\omega^{2}-\omega_{i}{ }^{2}\right)^{1 / 2}, & \epsilon & =\omega_{i} / n \\
\delta & =J j_{p} / j_{e}, & r & =E_{0} b^{2} N
\end{array}\right\},
$$

we obtain

$$
\begin{aligned}
& T S=\left[\left(\frac{2}{\pi}\right)^{2} \frac{\operatorname{Ir} \mu}{\omega_{i}}\right] \int_{0}^{\cos ^{-1} \epsilon} \sin \phi \cos \phi \int_{0}^{\infty}\left(z^{2}+1\right)^{-1 / 2} \\
& \times\left\{1+\left[\mu \nu\left(z^{2}+1\right)^{1 / 2} \cot (\phi-\delta)\right]^{s}\right\}^{-t / s} d z d \phi .(\mathrm{A} 12
\end{aligned}
$$

Desaubies (1976) gives an approximate result for the towed spectrum when $t=s=2$ (GM76),
$\Delta=0$ (no low-mode cutoff), and $\alpha \gg \alpha_{*}$ (a highwavenumber result). Eq. (A12) then reduces to

$$
\begin{aligned}
T S=\left(\frac{2}{\pi}\right)^{3} \frac{r \mu}{\omega_{i}} \int_{0}^{\cos ^{-1} \epsilon} & \sin \phi \cos \phi \int_{0}^{\infty}\left(z^{2}+1\right)^{-1 / 2} \\
& \times\left[\mu \nu\left(z^{2}+1\right)^{1 / 2} \cot \phi\right]^{-2} d z d \phi,
\end{aligned}
$$


TABLE A1. Model parameters.

\begin{tabular}{lllllll}
\hline \hline & $s$ & $t$ & $j_{e}$ & $j_{p}$ & \multicolumn{1}{c}{$J$} & \multicolumn{1}{c}{$I$} \\
\hline GM72 & $\infty$ & $\infty$ & 20 & 0 & 1 & 1 \\
GM75 & 1 & 2.5 & 11 & 0 & 1.8 & 1.5 \\
GM76 & 2 & 2 & 10 & 0 & $\pi$ & $2 / \pi$ \\
IWEX* & 1.2 & 2.4 & $* *$ & 1.2 & 2.1 & 1.15
\end{tabular}

* Constant, rather than frequency-dependent values, are given

$$
j_{e}^{* *}=10\left[1+\left(\frac{\cos ^{2} \phi-\epsilon^{2}}{1-\epsilon^{2}}\right)^{10}\right] \text {. }
$$

which yields Desaubies's Eq. (7), exactly. Formula (A12) is valid for $\alpha \geqslant \Delta$, i.e., $\mu \nu\left(z^{2}+1\right)^{1 / 2} \cot \phi$ $\geqslant \delta$. When this condition is not met, the towed spectrum vanishes. Note that the independent variable $\alpha$ only appears in the combination $\mu \nu=(\mathrm{JNb} /$ $\left.j_{e} \pi \delta_{i}\right) \alpha$, hence the shape of the towed spectrum is not a function of depth through the buoyancy frequency $n$.

The towed vertical coherence at a vertical separation $Y$ is $T V C(\alpha ; Y)$ :

$$
\begin{aligned}
T V C=(T S)^{-1} & \frac{2}{\pi} \int_{\omega_{1}}^{n} \int_{\alpha}^{\infty}\left(\alpha_{1}^{2}-\alpha^{2}\right)^{-1 / 2} E\left(\alpha_{1} \omega\right) \overline{Z^{2}} \\
& \times \cos \left[\frac{n Y \alpha_{1} 2 \pi}{\left(\omega^{2}-\omega_{i}^{2}\right)^{1 / 2}}\right] d \alpha_{1} d \omega .
\end{aligned}
$$

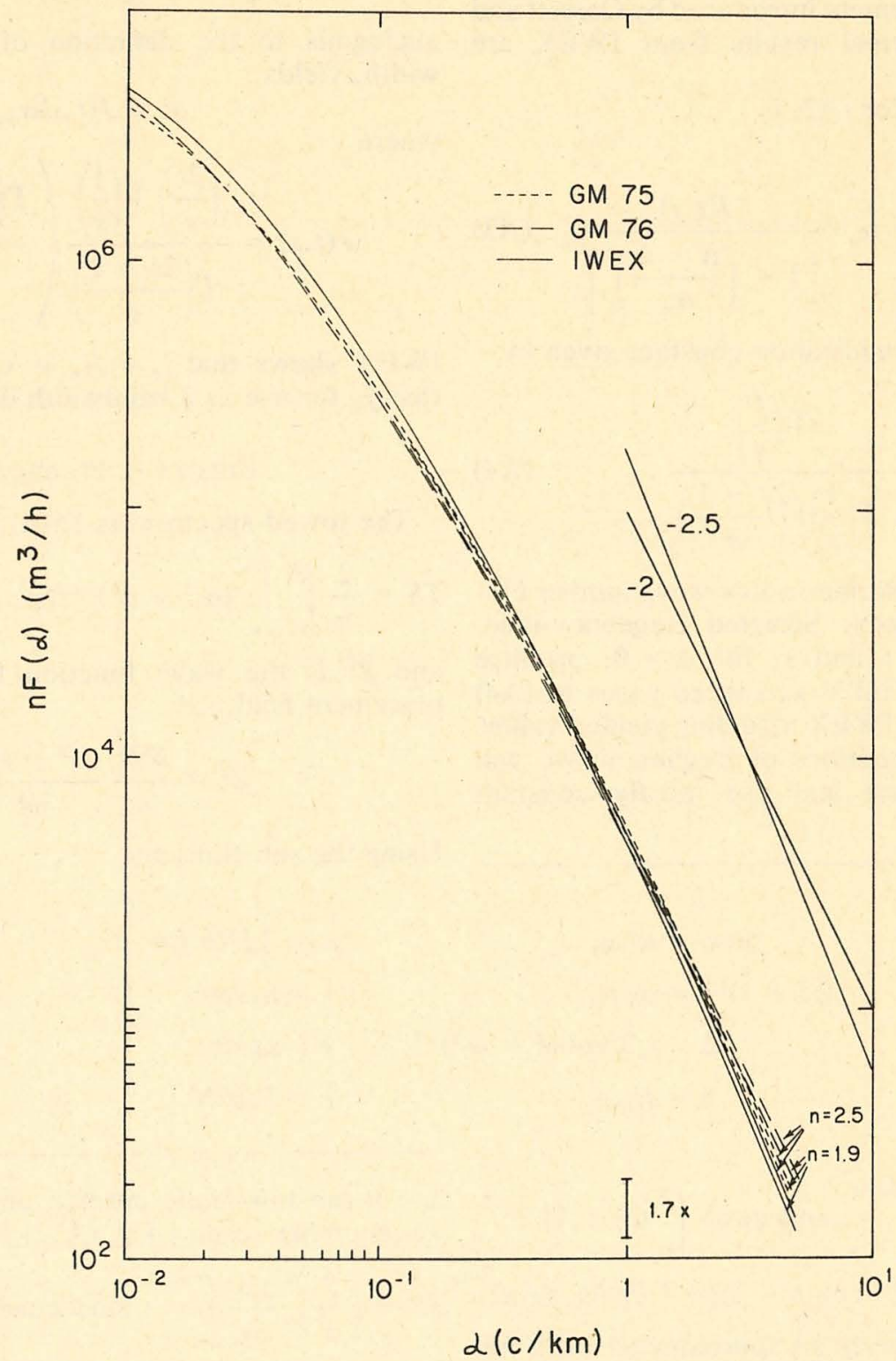

FIG. A1. Model predictions of the autospectrum of the vertical displacement of an isotherm scaled by the local buoyancy frequency. 

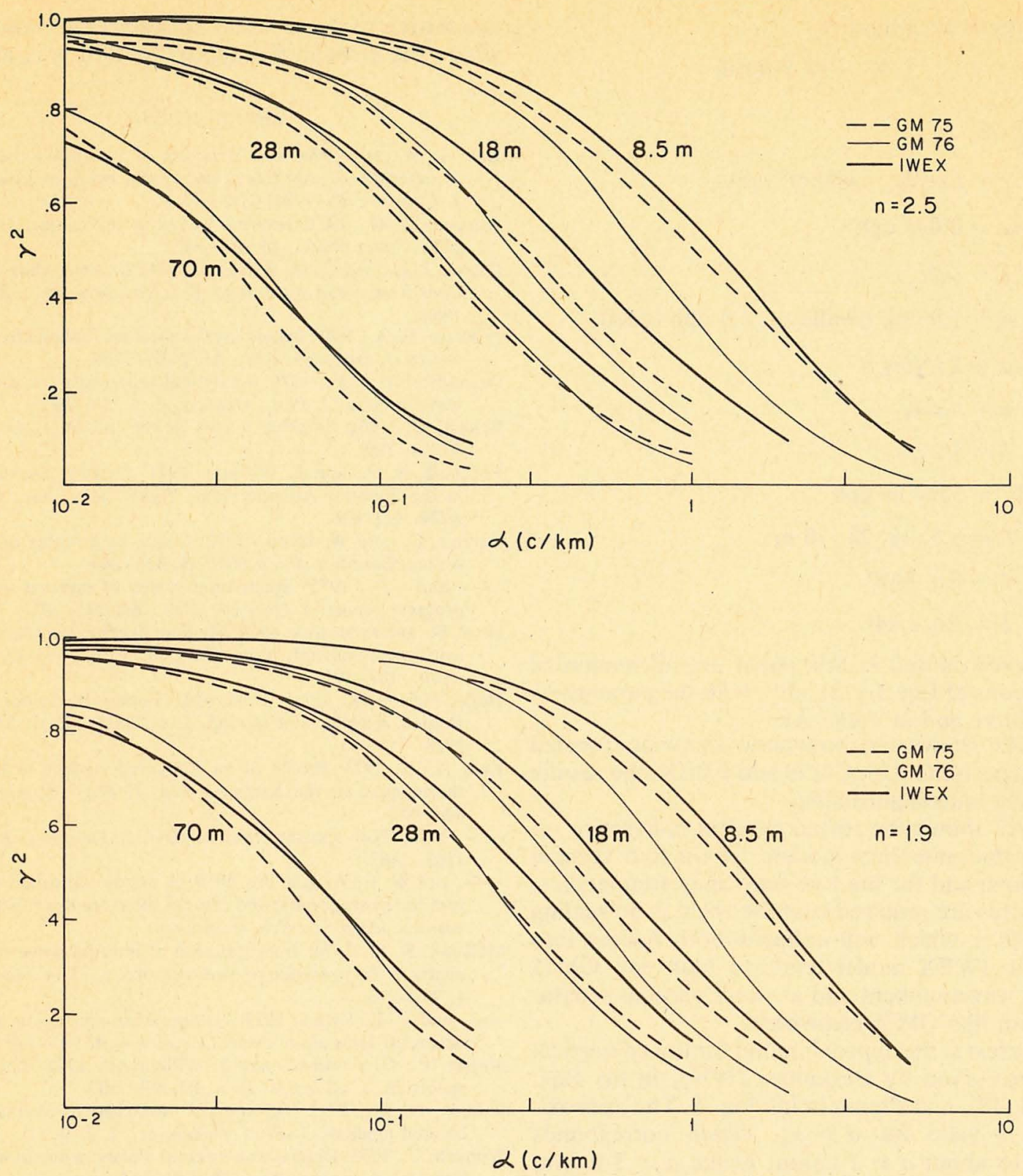

FIg. A2. Model predictions of the vertical squared-coherence spectra for $n=2.5$ and $1.9 \mathrm{cph}$.

$Q(Y)=\int_{0}^{\cos ^{-1} \epsilon} \sin \phi \cos \phi \int_{0}^{\infty}\left(z^{2}+1\right)^{-1 / 2}$

$\times\left\{1+\left[\mu \nu\left(z^{2}+1\right)^{1 / 2} \cot (\phi-\delta)\right]^{s}\right\}^{-t / s}$

then

$$
\times \cos \left[2 \pi \nu Y\left(z^{2}+1\right)^{1 / 2} \cot \phi\right] d z d \phi, \quad(\mathrm{A} 14)
$$

$$
\operatorname{TVC}(\alpha ; Y)=\frac{Q(Y)}{Q(0)} .
$$

The variable $\alpha$ now enters through both $\mu \nu$ and $\nu Y$.

The evaluation of $Q(Y)$, whence $T V C$, depends upon a number of parameters; these are listed in Table A1 for the various spectral models.
The various results are herewith collected together:

Basic function

$$
Q(Y)=\text { Eq. (A14) }
$$

Towed spectrum

$$
T S=\left(\frac{2}{\pi}\right)^{2} \frac{\operatorname{Ir} \mu}{\omega_{i}} Q(0)
$$

Towed cross spectrum

$$
T X S=\left(\frac{2}{\pi}\right)^{2} \frac{\operatorname{Ir} \mu}{\omega_{i}} Q(Y)
$$


Towed vertical coherence

$$
T V C=Q(Y) / Q(0)
$$

\section{Parameters}

$$
\begin{aligned}
r & =E_{0} b^{2} N=430 \mathrm{~m}^{2} \mathrm{cph} \\
\omega_{i} & =0.044 \mathrm{cph} \\
\epsilon & =\omega_{i} / n \\
n & =1.9 \mathrm{cph} \text { (shallow), } 2.5 \mathrm{cph} \text { (deep) } \\
\mu & =2 J N b / j_{e} n \\
\nu & =n \alpha / \omega_{i} \\
\delta & =J j_{p} / j_{e} \\
\mathrm{Nb} & =5500 \mathrm{~m} \cdot \mathrm{cph} \\
Y & =8.5,18,28,70 \mathrm{~m} \\
J & =\text { Eq. (A8) } \\
I & =\text { Eq. (A4). }
\end{aligned}
$$

The curves plotted in this paper are all numerical calculations of Eqs. (A12), etc., with the parameters given above and in Table A1.

Fig. A1 shows the buoyancy frequency scaled autospectra for GM75, GM76 and IWEX: the results are nearly indistinguishable.

Fig. A2 shows the towed vertical coherence results for the same three models, for the four vertical separations and for the two buoyancy frequencies. Two figures are required because there is no scaling of $\alpha$ with $n$ which will collapse both figures into one. The IWEX model tends to look like GM75 at large wavenumbers and at small vertical separations, and like GM76 elsewhere.

Of interest is the approximation for towed vertical coherence given by Desaubies (1976), in his Eqs. (17) and (18), and shown in his Fig. 5. The approximation is valid for $\alpha \gg \alpha_{*}$, which corresponds strictly to about $\alpha \gg 1 \mathrm{cpkm}$, hence $\alpha \geqslant 3 \mathrm{cpkm}$, say. However, his curve is still useful simply because its shape is approximately correct, which is due to the towed vertical coherence being relatively insensitive to those small horizontal wavenumbers where the error in the approximation is large.

\section{REFERENCES}

Bell, T. H., Jr., 1976: The structure of internal wave spectra as determined from towed thermistor chain measurements. J. Geophys. Res., 81, 3709-3714.

Briscoe, M. G., 1975: Internal waves in the ocean. Rev. Geophys. Space Phys., 13, 591-645.

Cairns, J. L., and G. O. Williams, 1976: Internal wave observations from a mid-water float, 2. J. Geophys. Res., 81, 1943 1950.

D'Asaro, E. A., 1978: Mixed layer velocities induced by internal waves. J. Geophys. Res., 83, 2437-2438.

Desaubies, Y. J. F., 1976: Analytical representation of internal wave spectra. J. Phys. Oceanogr., 6, 976-981.

Eckart, C., 1961: Internal waves in the ocean. Phys. Fluids, 4, 791-799.

Fofonoff, N. P., and F. Webster, 1971: Current measurements in the western Atlantic. Phil. Trans. Roy. Soc. London, A270, 423-436.

Garrett, C., and W. Munk, 1972: Space-time scales of internal waves. Geophys. Fluid Dyn., 3, 225-264.

_ , and _ 1975: Space-time scales of internal waves: A progress report. J. Geophys. Res., 80, 291-297.

Hess, F., and R. Nowak, 1974: Medium depth controllable towed instrument platform. Proc. IEEE Int. Conf. Eng. Ocean Environ., 187-191.

Hogg, Nelson G., Eli J. Katz and Thomas B. Sanford, 1978: Eddies, islands, and mixing. J. Geophys. Res., 83, 29212938.

Katz, E. J., 1973: Profile of an isopycnal surface in the main thermocline of the Sargasso Sea. J. Phys. Oceanogr., 3, $448-457$.

, 1975: Tow spectra from MODE. J. Geophys. Res., 80, $1163-1167$.

—, and W. E. Witzell, Jr., 1979: A depth-controlled tow system for hydrographic and current measurements with applications. Deep-Sea Res. (in press).

McKean, R. S., 1974: Interpretation of internal wave measurements in the presence of finestructure, J. Phys. Oceanogr., $4,200-213$.

—, and T. E. Ewart, 1974: Temperature spectra in the deep ocean off Hawaii. J. Phys. Oceanogr., 4, 191-199.

Müller, P., D. J. Olbers and J. Willebrand, 1978: The IWEX spectrum. J. Geophys. Res., 83, 479-500.

Phillips, O. M., 1971: On spectra measured in an undulating layered medium. J. Phys. Oceanogr., 1, 1-6.

Wunsch, C., 1975: Deep ocean internal waves: what do we really know? J. Geophys. Res., 80, 339-343.

Zenk, W., and E. J. Katz, 1975: On the stationarity of temperature spectra at high horizontal wave numbers. J. Geophys. Res., 80, 2885-2891. 



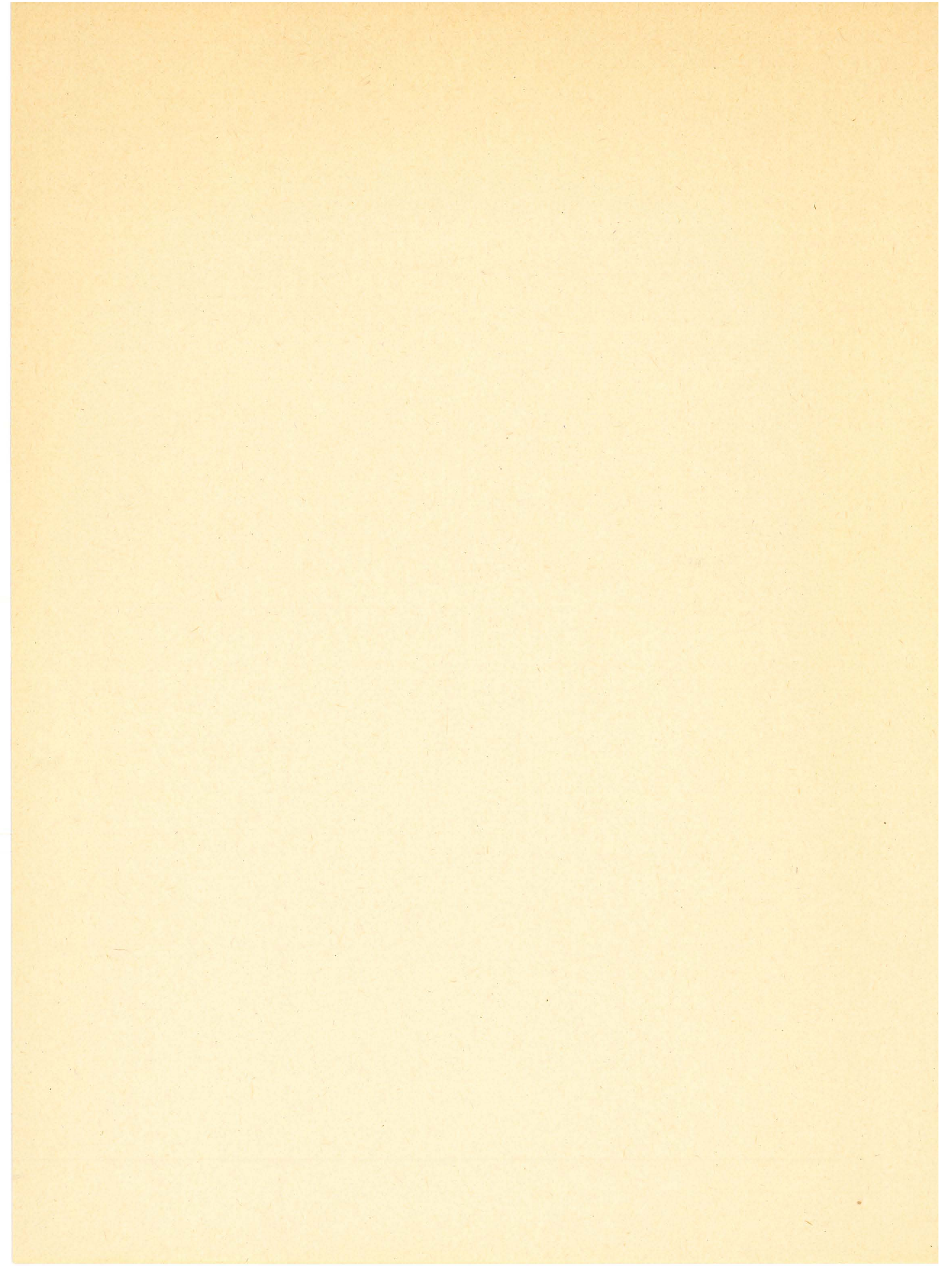


MANDATORY DISTRIBUTION LIST

FOR UNCLASSIFIED TECHNICAL REPORTS, REPRINTS, AND FINAL REPORTS PUBLISHED BY OCEANOGRAPHIC CONTRACTORS

OF THE OCEAN SCIENCE AND TECHNOLOGY DIVISION

OF THE OFFICE OF NAVAL RESEARCH

(REVISED NOVEMBER 1978)

1 Deputy Under Secretary of Defense

(Research and Advanced Technology)

12 Defense Documentation Center

Military Assistant for Environmental Science

Room 3D129

Washington, D.C. 20301

Office of Naval Research

800 North Quincy Street

Arlington, VA 22217

3 ATTN: Code 483

1 ATTN: Code 460

2 ATTN: 102B

1 CDR J. C. Harlett, (USN)

ONR Representative

Woods Hole Oceanographic Inst.

Woods Hole, MA 02543

Cameron Station

Alexandria, VA 22314

ATTN: DCA

Commander

Naval Oceanographic Office

NSTL Station

Bay St. Louis, MS 39522

1 ATTN: Code 8100

1 ATTN: Code 6000

1 ATTN: Code 3300

Commanding Officer

Naval Research Laboratory

Washington, D.C. 20375

6 ATTN: Library, Code 2627

1 NODC/NOAA

Code D781

Wiscons in Avenue, N.W.

Washington, D.C. 20235 



\begin{tabular}{|c|c|}
\hline REPORT DOCUMENTATION PAGE & $\begin{array}{l}\text { READ INSTRUCTIONS } \\
\text { BEFORE COMPLETING FORM }\end{array}$ \\
\hline $\begin{array}{l}\text { 1. REPORT NUMGER } \\
\text { WHOI-79-101 }\end{array}$ & 3. RECIPIENT'S CATALOG NUMBER \\
\hline \multirow{2}{*}{$\begin{array}{l}\text { 4. TITLE (and Subtlile) } \\
\text { VERTICAL COHERENCE OF THE INTERNAL WAVE FIELD } \\
\text { FROM TOWED SENSORS }\end{array}$} & $\begin{array}{l}\text { 5. TYPE OF REPORT \& PERIOD COVERED } \\
\text { Technical }\end{array}$ \\
\hline & $\begin{array}{l}\text { 6. PERFORMING ORG. REPORT NUMBER } \\
\text { WHOI CON. NO. } 4205\end{array}$ \\
\hline $\begin{array}{l}\text { 7. AUTHOR(e) } \\
\text { Eli J. Katz and Melbourne G. Briscoe }\end{array}$ & $\begin{array}{l}\text { 8. CONTRACT OR GRANT NUMBER(s) } \\
\text { NO0014-74-C-0262; } \\
\text { OCE 74-19608 }\end{array}$ \\
\hline $\begin{array}{l}\text { 9. PERFORMING ORGANIZATION NAME AND ADDRESS } \\
\text { Woods Hole Oceanographic Institution } \\
\text { Woods Hole, MA } 02543\end{array}$ & $\begin{array}{l}\text { 10. PROGRAM ELEMENT, PROJECT, TASK } \\
\text { AREA Q WORK UNIT NUMBERS } \\
\text { NR } 083-004\end{array}$ \\
\hline \multirow{4}{*}{$\begin{array}{l}\text { 11. CONTROLLING OFFICE NAME AND ADDRESS } \\
\text { NORDA } \\
\text { National Space Technology Laboratory } \\
\text { Bay St Lyis MS } 39529 \\
\text { 14. MONNITRING AGENCY AME ADDRES(If dilferent from Controlline Ollice) }\end{array}$} & $\begin{array}{l}\text { 12. REPORT DATE } \\
\text { December } 1979 \\
\end{array}$ \\
\hline & 13. NUMBER OF PAGES \\
\hline & $\begin{array}{l}\text { 15. SECURITY CLASS. (of thio roport) } \\
\text { Unclassified }\end{array}$ \\
\hline & $\begin{array}{l}\text { 15a. DECLASSIFICATION/DOWNGRADING } \\
\text { SCHEDULE }\end{array}$ \\
\hline
\end{tabular}

16. DISTRIBUTION STATEMENT (ol thla Roport)

Approved for public release; distribution unlimited.

17. DISTRIBUTION STATEMENT (of the abetract ontored in Block 20, if different from Repopt)

18. SUPPLEMENTARY NOTES

Reprinted from "Journal of Physical Oceanography, Vo1. 9, No. 3, May 1979, pp. 518-530".

19. KEY WORDS (Continus on poveree alde if neceesery and tdentify by block number)

1. Internal waves

2. Eckart resonance

3. Towed coherence of internal waves

20. AESTRACT (Continue on reveres alde if neceseery and ldentlly by block number)

Constant depth and isopycnal-following tows are used to estimate the towed vertical coherence of the internal wave field, at vertical separations of $8.5,18,28$ and $70 \mathrm{~m}$. The depths of the tows are $\sim 750 \mathrm{~m}$ at the maximum of the buoyancy frequency in the main thermocline of the Sargasso Sea, and near $350 \mathrm{~m}$ in the buoyancy frequency minimum between the main and seasonal thermoclines.

(Cont. on back) 
The towed spectra and towed vertical coherence are compared with three model spectra (GM75, GM76 and IWEX); at $750 \mathrm{~m}$ the agreement between data and models is very good, with IWEX being slightly better. At $350 \mathrm{~m}$, several of the measured towed vertical coherence spectra are more complex than the spectra from the deeper tows; there are anomalously high coherences in a band from 0.7 to 2 cycles per kilometer that are not predictable by the models. We suggest this coherence bump may be evidence of Eckart resonance, i.e., modes tunneling between the two thermoclines into the region of low buoyancy frequency. 


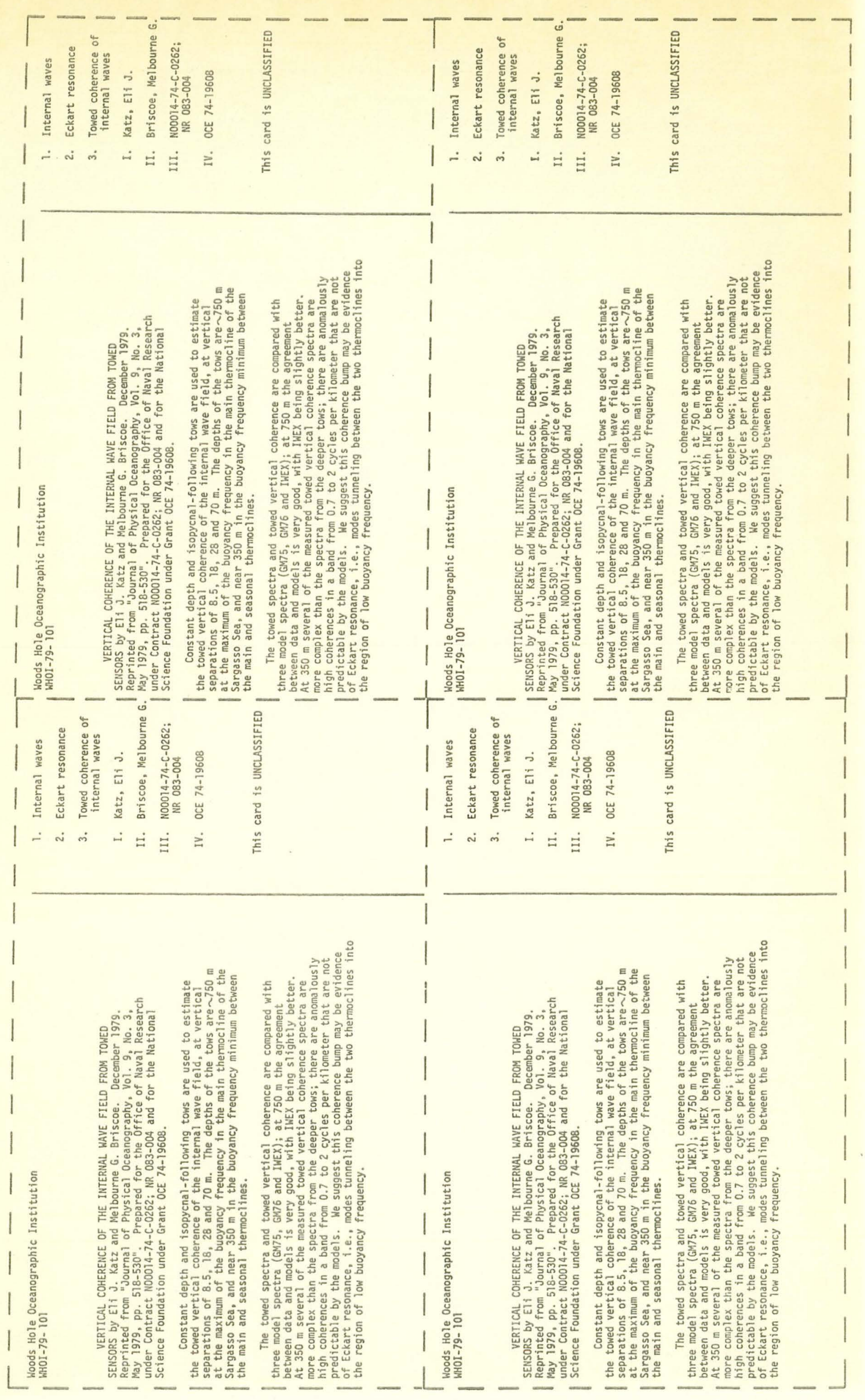

